\title{
Manual de los Reglamentos del Agua en Florida: Departamento de Agricultura y Servicios al Consumidor de Florida ${ }^{1}$
}

Michael T. Olexa, Luke D'Isernia, Laura Minton, Dulcy Miller y Sara Corbett ${ }^{2}$

\section{Prefacio}

Este manual esta diseñado para proporcionar un resúmen autorizado, exacto y actual de las principales leyes Federales y de Florida que están directa o indirectamente relacionadas a la agricultura. Este manual debe proveer una vista general de los muchos derechos y responsabilidades que tienen los agricultores y propietarios de tierras agrícolas bajo las leyes tanto Federal como de Florida, así como también la información de los contactos apropiados para obtenerla con más detalle. Sin embargo, el lector debe estar advertido de que algunas partes de esta publicación podrían volverse obsoletas en cualquier momento, debido a que las leyes, reglas administrativas, y decisiones de la corte, sobre las cuales se basa este manual, se encuentran bajo revisión constante. Algunos detalles de las leyes citadas no se mencionan, debido a limitaciones de espacio.
Este manual es distribuido con la aclaración de que los autores no intentan proporcionar una asesoría legal o profesional, y que la información contenida aquí no debe ser considerada como un sustituto de asesoría profesional. En este manual, no se incluye toda la información para llevar a cabo el cumplimiento de las leyes Federales y de Florida y los reglamentos que rigen la protección del agua. Por estas razones, el uso de estos materiales por cualquier persona, constituyen un acuerdo para mantener libre de perjuicios a los autores, al Servicio de Extensión Cooperativa de Florida, al Instituto de los Alimentos y Ciencias Agrícolas y a la Universidad de Florida por reclamos de responsabilidad, daños o gastos provenientes de quien sea, por haberse referido o basado en la información contenida en este manual.

1. Este es el documento EDIS FE079, una publicación de Food and Resource Economics Department, Florida Cooperative Extension Service, Institute of Food and Agricultural Sciences, University of Florida, Gainesville, FL. Publicado Noviembre 2006. Por favor visite la página electrónica de EDIS en http://edis.ifas.ufl.edu.

2. Michael T. Olexa, profesor, Food and Resource Economics Department y director, Agricultural Law Center, University of Florida, Gainesville, FL, y presidente, Agricultural Law Committee, The Florida Bar; Luke D'Isernia, alumni, Levin College of Law, University of Florida, Gainesville, FL; Laura Minton, abogado, Dean, Mead, Egerton, Bloodworth, Capouano y Bozarth, PA, Orlando FL; Dulcy Miller, abogado, Foley and Lardner, LLP, Orlando, FL; y Sarah Corbett, abogado, Florida Second District Court of Appeal, Lakeland, FL. La traducción del ingles al español estuvo a cargo de Filiberto Reyes-Villanueva.

El Instituto de Alimentos y Ciencias Agrícolas es un empleador que opera bajo Acción Afirmativa y provee Oportunidades Igualitarias, autorizado a proveer investigación, información educativa y otros servicios, únicamente a los individuos e instituciones que operan sin discriminación alguna con relación al credo, color, religión, edad, incapacidad, sexo, orientación sexual, estado civil, nacionalidad, opinion política o afiliaciones. Para más información sobre como obtener otras publicaciones de extensión, comuníquese con la oficina de Servicio de Extensión de su condado. Servicio de Extensión de la Florida / Instituto de Alimentos y Ciencias Agrícolas / Universidad de la Florida / Larry Arrington, Decano. 


\section{Vista General}

El Departamento de Agricultura y Servicios al Consumidor (DASC) lleva a cabo funciones relacionadas con las practicas agrícolas y productos, que garanticen la seguridad y sanidad de los alimentos y otros productos de consumo, a través de programas de inspección y pruebas, asistiendo a los agricultores e industria agrícolas de Florida en la producción y promoción de productos agrícolas; y conservando y protegiendo la agricultura del estado y los recursos naturales para la reducción de los incendios forestales, la promoción de prácticas ambientalmente seguras para la agricultura y manejo de la tierra pública. Las responsabilidades incluyen:

- El registro, etiquetado e inspección de los fertilizantes comerciales, plaguicidas, gasolina y aceites.

- El registro (ej., autorizando y reglamentando) de los aplicadores de plaguicidas.

- Conservación del suelo y agua.

El DASC esta dividido en diecinueve divisiones, cada una con temas separados, como se ilustra en las siguientes cuatro divisiones:

- División de Servicios de Agricultura y Medio Ambiente regula y autoriza a los operadores de control de plagas y provee asistencia a los Distritos de Conservación del Suelo y el Agua. Dentro de esta división está la Oficina de Plaguicidas la cual registra los plaguicidas vendidos y usados en el estado y supervisa los programas de plaguicidas que están relacionados con la protección de la salud pública y el medio ambiente. La Oficina de Entomología y Control de Plagas las cuales protegen la salud de los consumidores de Florida y seguridad del medio ambiente a través del control efectivo de los mosquitos y regulación del control de plagas. También ayuda en asegurar el cumplimiento de la Ley Federal de Insecticidas, Plaguicidas y Rodenticidas bajo un acuerdo cooperativo con la APA. La Oficina de los Laboratorios de Alimentos, Semilla y Fertilizantes, a través de sus programas de de alimentos y semillas, examinan las muestras de estos para asegurar que los consumidores reciban productos de calidad, proporcionar un nivel standard para todos los fabricantes, y promueve la supervisión total del medio ambiente. La división también incluye la Oficina de Conservación del Suelo y el Agua.

- División de Estandares es responsable, por medio de sus Oficinas de Inspecciónes Justas ( http://www.doacs.state.fl.us/standard/fairs/ index.html). Inspección de Petróleo de Gas Liquido (

http://www.doacs.state.fl.us/standard/lpgas/ index.html). Inspección de Licuado de Petróleo

( http://www.doacs.state.fl.us/standard/petro/ index.html) y la Inspección de Pesos y Medidas (http://www

doacs.state.fl.us/standard/weights/index.html), para la protección de los consumidores de las practicas comerciales ilegales e injustas que abarcan un amplio rango de productos, incluyendo gasolina, liquido de frenos, anticongelante, gas liquido de petróleo, servicios de viajes de entretenimiento y dispositivos de pesaje y medidas.

- División de Forestales maneja los recursos forestales. Dentro de la división esta la Oficina de Servicios de Planificación que incluye la Sección de Protección de las Cuencas (SPC). Esta Sección ofrece los servicios de hidrologia profesional (ciencia del uso del agua) para el público y otras agencias del estado. También es responsable por el desarrollo de elementos de la silvicultura (forestal) del Plan de la Calidad del Agua del Estado (ver FE077), Distritos de Manejo del Agua). Lo más importantes es, la SPC monitorea el impacto del reglamento del agua sobre bosques y podría ser más útil en ayudar a los agricultores en manejar cualquier recurso forestal que éste pueda poseer.

- División de Administración maneja las funciones del Departamento de Agricultura y Servicios al Consumidor. Esta división incluye la Oficina del Cumplimiento de las Leyes Agrícolas, la cual provee la inspección de 
productos agrícolas. También incluye las

Oficinas de Finanzas, Contabilidad y Servicios

Generales, Manejo de Personal, Planificación y

Presupuesto, Entrenamiento y Desarrollo, y el

Centro de Información para el Manejo de la

Agricultura.

El DASC también incluye la Oficina de la Política del Agua Agrícola (OPAA), la cual permite la comunicación entre las agencias federales, estatales y locales y la industria agrícola, para la calidad y cantidad de agua y los temas que involucren la agricultura. La OPAA esta activamente involucrada en el desarrollo de las Prácticas de Mejor Manejo (PMM), centrándose tanto en la calidad del agua como en la conservación de la misma en un sitio especifico, regionales y cuencas.

\section{Agradecimientos}

Los autores agradecen al personal de las agencias estatales y federales por su tiempo y asesoría en la preparación de este manual. Los autores agradecen especialmente a Richard Budell del Office of Agricultural Water Policy of the Florida Department of Agriculture and Consumer Services por el apoyo económico para el desarrollo de esta publicación. 